\title{
Heat Exchanger Dynamic Analysis
}

\author{
R. Whalley and K. M. Ebrahimi* \\ Department of Aeronautical and Automotive Engineering \\ Loughborough University, UK. \\ * corresponding author
}

\begin{abstract}
.
The modelling and dynamic analysis of shell and tube heat exchangers will be considered in this contribution. Procedures which incorporate the heat transfer and the fluid flow system properties, for these processes, will be developed. An incremental, energy balance yielding the system, partial differential equations presents the governing process. The multivariable, multi-dimensional, Laplace transformed, distributed parameter formulation of heat exchanger representations, are provided. A frequency domain description of the system model is derived enabling the recovery of Laplace function rationality for both parallel and counter flow heat exchanger models. Suitable feedback control techniques are identified, as a prelude to closed loop design studies. The dynamics, for tubular heat exchangers are computed, for purposes of comparison with alternative response and regulation approaches. A typical application study is outlined.
\end{abstract}

Keywords: heat, exchanger, modelling, response, dynamics. 


\section{Nomenclature}

$\theta_{h} \quad$ High temperature fluid stream scalar

$\theta_{l} \quad$ Low temperature fluid stream scalar

$\varphi \quad$ Tube wall temperature scalar

$v_{l} \quad$ Low temperature fluid flow velocity scalar

$v_{\boldsymbol{h}} \quad$ High temperature fluid flow velocity scalar

R Tube material conductance scalar

Z Distance from inlet scalar

L Effective length of tubes scalar

$C_{h} \quad$ Heat capacitance of high temperature fluid steam scalar

$C_{l} \quad$ Heat capacitance of low temperature fluid steam scalar

$I_{m} \quad$ Identity array matrix

Z Ratio Z/L scalar

r Ratio $v_{h} / v_{l}$ scalar

$\mathrm{U}(\mathrm{s}) \quad$ Eigenvector array matrix

y(s) System output signals vector

u(s) System input signals vector

$\boldsymbol{D}=\partial / \partial \boldsymbol{t}$ Time differential operator

$\tau_{1}, \tau_{2} \quad$ Valve and heater time constants $\quad$ scalars

$\boldsymbol{G}(\boldsymbol{s}), \overline{\boldsymbol{G}}(\boldsymbol{s}) \quad$ Transfer function arrays matrix

$\lambda_{1}(s), \lambda_{2}(s)$ Eigenvalues function

$\gamma_{1}(s), \gamma_{2}(s) \quad$ Eigenvectors function

$\delta_{1}(s), \delta_{2}(s) \quad$ Ambient disturbance signals scalar

$V_{1}(s), V_{2}(s) \quad$ Valve input voltages $\quad$ scalars 


\section{Introduction}

Heat exchangers are used in many industries where fluid heat transfer is required, see for example Saunders E.A (1). In this operation heat energy is transferred from a hot to a cooler fluid flow stream by a carrier type, energy conversion process, as in Hewitt G et al (2) and Coulson. H. G and Richardson J. (3). This involves coupled fluid flow and thermal interactions where heat is transferred along with the fluid flow through the containing volumes and across the separating, heat exchanger, tube walls.

The heating of materials during conveyancing operations would also be equivalent to a carrier flow, heat transfer, percolation process. Continuous conveyor fed food preparation systems and the fluid drainage from the pulp-fibre suspensions, in the paper and board manufacturing industries, as detailed in Smith B.W (4), for example, also comprise percolation, heat and mass transfer processes.

However, in this compilation the large scale, tubular heat transfer units commonly employed in the oil, gas and chemical industries, as discuss in Sadik K and Liu H. (5), and Smith E.M (6) will be the focus of the formulation, analysis and simulation studies presented herein. These devices are also used in ventilation, air conditioning and battery cooling systems, as detailed in Whalley R and Ameer A (7), Roetzel, W. and Xuan, Y. (8) in refrigeration units, in fossil fuel boilers, see for example Whalley R (9) and in nuclear, electrical power generation plant, as shown in Schultz M.A. (10).

Generally, tubular heat transfer units are configured to work in series with a fluid source of supply and a suitable coolant or heating, fluid stream. A continuous process is employed thereafter to simultaneously achieve, the parallel or counter flow, heating or cooling effect required. 
To maximize heat transfer the hottest and coolest fluid/ gas flows may be initially interfaced, in a parallel flow arrangement, as shown in figure 1 a and in Lienhard H. and Lienhard H. (11). Otherwise, an alternative energy exchange mechanism can be provided, via a suitable tubeshell counter flow design, as shown in Kraus A.D. et al (12), and indicated by figure 1b.

Generally, heat exchanger models are unsuitable for automatic regulation studies owing to the non-linear distributed parameter, irrational functions arising. The novelty of the analysis presented herein shows that linear, transient representations can be determined where as frequency response analysis enables function rationality to be recovered inviting conventional, feedback design methods.

\section{Tubular Heat Exchangers}

The commonest type of heat exchanger and heat transfer devices comprise an outer shell and an inner, multiple tube construction, as shown in figure 2. Owing to this design, the dynamic modelling process, is aimed at replicating the interaction of the hot and cold fluids or gases and their distance- velocity, finite time delay attributes, as in Bennett C.O. and Myers J.E (13), Taler D (14) and (15).

A single tube arrangement will be employed in the procedure outlined herein, as shown in figure 3, for a parallel flow unit. This figure could also be used to depict a counter flow heat exchanger, by reversing the direction of the shell flow fluid and by changing $\theta_{l_{2}}$ to $\theta_{l_{1}}$ and $\theta_{l_{1}}$ to $\theta_{l_{2}}$.

The expansion of the capacity of these units to include the multiple tube and shell arrangements which are employed in industry could be facilitated by increasing the fluid flow 
rates and the number of tubes employed. Industrial heat exchangers are usually fitted in practice with internal baffle plates, to maximize the length of the gas or fluid path and hence the surface, heat transfer exposure, of the tube assembly, as in Congel Y.A (16). The shell and internal tube configuration, of heat exchangers results in a dynamic system model with the generation two distinct, independent, finite time delays, see for example, Taler D. (17).

Owing to the non-linear representation of heat exchangers work to determine formulations which would be suitable for automotive battery cooling regulation, as herein, is current.

The finite time delays arise from the shell, fluid/ gas flow dynamics and from the tube fluid or gas flow, transportation delays from the respective shell and tube, input and output ports. This property means that the input- output representations, for tubular heat exchanger models, arise from the simultaneous solution of partial differential equations, see for example DuChateau P and Zachmann D. (18), governing the fluid-gas transportation and the process, heat flow dynamics. Consequently, under independent, input - output fluid flow conditions, the system transfer function model reflects the dynamic shell and tube fluid or gas temperature and flow conditions, respectively. This model would also be two dimensional, see for example Jost J (19), due to the two Independent, finite time delays representing the distance - velocity lags which characterize the fluid flow streams as shown in Korzen A, Taler D (20).

All aspects of performance may be routinely included in the two dimensional, multivariable, modelling process, as in Whalley R. (21). However, the analysis and regulation of heat exchangers becomes a challenging task owing to the Laplace function incompleteness arising as part of the modelling process, and from the multivariable, distributed parameter and multidimensional nature of the problem, see for example Whalley R. and Zeng Z. (22). 
These features are difficult to accommodate within the conventional range of closed loop, system analysis/ design procedures, given in Schwartz. R.S and Friedland B. (23) and in Dutton. $\mathrm{K}$, et al (24), leading to many approximate, heuristic and empirical approaches to the regulation problem, as described in Rosenbrock H.H (25) and Reddy J.N. (26). Under balanced, symmetrical flow conditions when the finite delays for the shell and tube, fluid/ gas flow rates are equal, the system input- output, transfer functions become dependent on a single, finite time delay. This removes the Laplace incompleteness issue and the multidimensional function problem, for these particular, special case operating conditions.

In general, of course, input- output flow and temperature balancing may not be possible when the achievement of specified heat transfer rates and hence the attainment of particular, timedistance- temperature gradients, along the heat exchanger tubes, is necessary.

Fine adjustment with the inclusion of pre and / or post heaters or coolers in the design may often be necessary, to achieve specified gas/ fluid temperature profiles. Although attracting further cost, complexity and energy expenditure these compensating units are often required to achieve particular fluid or gas flow, output temperatures.

To facilitate future automatic regulation studies, a general fluid flow modelling approach will be adopted herein based on the early research, presented by Profos P. (27). However his model results in an irrational, incomplete Laplace representation which is difficult to apply in practice, owing to the analytical and Laplace inversion issues arising which are addressed herein.

In this regard, all of the conventional, multivariable approaches required for Optimal and $\mathrm{H}$ Infinity, Inverse Nyquist and Characteristic Locus techniques, provided in Maciejowski J.M. (28) and Sala P.A. (29), would be unable to accommodate irrational, multivariable, 
multidimensional, controller design. These procedures require multivariable, linear, single dimensional, rational, complete Laplace models excluding thereby, tubular heat exchanger, feedback regulator problems. However, recent work by Whalley R and Ebrahimi K. M. (30),(31), shows promise in this regard, by employing least effort regulation.

\section{Analysis}

The percolation, heat transfer analysis, for parallel or counter flow heat exchangers, commences with a dynamic, energy balance, for a fluid increment, as in Profos P. (27), when considering an equivalent, single tube- shell arrangement.

The combined fluid flow- heat transfer mechanism for a fluid element indicates that the:

heat stored by a tube contained, fluid increment of length $d z=$ Heat carried by the incremental fluid flow- heat transferred to an adjacent fluid increment+ heat transferred from the heat exchanger, tube wall to the fluid increment, as in Incoopera F.P. et al (32), Romic F.E. (33) and (34).

Consequently, the dynamic heat dissipation equation is given by:

$$
C d Z\left(\frac{\partial \theta}{\partial t}\right) d t=v C \theta d t-v C\left(\theta+\frac{\partial \theta}{\partial Z} d Z\right) d t+\frac{d Z}{R}(\varphi-\theta) d t
$$

Following division by $\boldsymbol{C d Z d t}$ Equation 3.1 results in:

$$
\frac{\partial \theta}{\partial t}=-v \frac{\partial \theta}{\partial Z}+\frac{(\varphi-\theta)}{R C}
$$

Equation 3.2 can be written for the high and low temperature fluid flow for a parallel or counter flow heat exchange as;

$$
\frac{\partial \theta_{h}}{\partial t}+v_{h} \frac{\partial \theta_{h}}{\partial Z}=\left(\theta_{l}-\theta_{h}\right) /\left(R C_{h}\right)
$$


and

$$
\frac{\partial \theta_{l}}{\partial t} \pm v_{l} \frac{\partial \theta_{l}}{\partial Z}=\left(\theta_{h}-\theta_{l}\right) /\left(R C_{l}\right)
$$

respectively, where in equations 3.3 and 3.4 the subscripts $\boldsymbol{h}$ and $\boldsymbol{l}$ indicate the high and low temperature flows of the fluid increment. In equation 3.4 the plus sign indicates a parallel and the negative sign is required for counter flow, heat exchanger analysis. This is required owing to the change in the temperature gradient where $\theta_{l, h}=\varphi=$ the tube wall temperature, for the high and low temperature fluid/ gas streams, respectively.

If: $\boldsymbol{L}=$ the effective length of the heat exchanger fluid path and with the ratio

$$
\begin{gathered}
\frac{L}{v_{h}}=L_{h} \text { and } \frac{L}{v_{l}}=L_{l} \text { then time scaling can } \\
t=\tau L_{h}=\tau \frac{L}{v_{h}} \text { and } \partial t=\partial \tau L_{h}
\end{gathered}
$$

With:

$$
z=Z / L, \text { so that } L \partial z=\partial Z \text {, }
$$

this allows Equation 3.3 to be written as:

$$
\frac{\partial \theta_{h}}{\partial \tau}+\frac{\partial \theta_{h}}{\partial z}=a_{h}\left(\theta_{l}-\theta_{h}\right), \quad a_{h}=L_{h} /\left(R C_{h}\right)
$$

also, if $\boldsymbol{L}_{l}=\boldsymbol{L} / v_{l}, r=v_{h} / v_{l}$ and again with time scaling with $t=\tau \boldsymbol{L}_{h}$, then

$$
r \frac{\partial \theta_{l}}{\partial \tau} \pm \frac{\partial \theta_{l}}{\partial z}=a_{l}\left(\theta_{h}-\theta_{l}\right), \text { where } a_{l}=L_{l} /\left(R C_{l}\right)
$$

This completes the formulation of the governing, heat exchanger equations.

\section{Matrix Representation.}

In the previous section, equations 3.6 and 3.7 can be written in matrix form as: 


$$
\frac{\partial}{\partial z}\left[\begin{array}{l}
\theta_{h}(t) \\
\pm \theta_{l}(t)
\end{array}\right]=\left[\begin{array}{cc}
-\left(a_{h}+D\right) & a_{h} \\
a_{l} & -\left(a_{l}+r D\right)
\end{array}\right]\left[\begin{array}{l}
\theta_{h}(t) \\
\theta_{l}(t)
\end{array}\right]
$$

where in equation $4.1 D=\partial / \partial \tau$. The eigenvalues of equation 4.1 are given by the solution to:

$$
\operatorname{det}\left[\begin{array}{cl}
\lambda+w_{11} & w_{12} \\
w_{21} & \lambda+w_{22}
\end{array}\right]=0
$$

where for a parallel flow heat excanger:

$$
\begin{aligned}
& w_{11}=a_{h}+D, w_{12}=-a_{h}, \\
& w_{21}=-a_{l} \text { and } w_{22}=a_{l}+r D
\end{aligned}
$$

and for a counter flow heat excanger:

$$
\begin{aligned}
& w_{11}=a_{h}+D, \quad w_{12}=-a_{h}, \\
& w_{21}=-a_{l} \text { and } w_{22}=-\left(a_{l}+r D\right)
\end{aligned}
$$

With a Laplace transformation to the frequency domain where: $\theta(s)=\boldsymbol{U}(\boldsymbol{s}) \bar{\theta}(s)$ is employed, as in Takahashi Y. et al (35) and Barnett S. (36), then for a parallel flow heat exchanger a diagonal representation can be obtained. In matrix form equation 4.2 becomes:

$$
s\left[\begin{array}{l}
\bar{\theta}_{h}(s) \\
\bar{\theta}_{l}(s)
\end{array}\right]=\left[\begin{array}{ll}
\lambda_{1}(s) & 0 \\
0 & \lambda_{2}(s)
\end{array}\right]\left[\begin{array}{l}
\bar{\theta}_{h}(s) \\
\bar{\theta}_{l}(s)
\end{array}\right]=\Lambda(s)\left(\bar{\theta}_{h}(s), \bar{\theta}_{l}(s)\right)^{T}:
$$

where in equation $4.3, \lambda_{1,2}(s)$ are the eigenvalue functions and $\Lambda(s)=\operatorname{diag}\left(\lambda_{1}(s), \lambda_{2}(s)\right)$ and the transformation, eigenvector matrix, is $\mathrm{U}(\mathrm{s})$ where:

$$
U(s)=\left[\begin{array}{ll}
1 & 1 \\
\gamma_{1}(s) & \gamma_{2}(s)
\end{array}\right]
$$

and the eigenvector elements can be determined as:

$$
\gamma_{1}(s)=\left(a_{h}+s+\lambda_{1}(s)\right) / a_{h} \text { and } \gamma_{2}(s)=\left(a_{h}+s+\lambda_{2}(s)\right) / a_{h}
$$

with the eigenvalues of equation 4.3 given by: 


$$
\lambda_{1,2}(s)=-0.5\left\{\left(w_{11}(s)+w_{22}(s)\right) \pm \sqrt{\left[\left(w_{11}(s)-w_{22}(s)\right)^{2}+w_{12}(s) w_{21}(s)\right]}\right\}
$$

If in equation 4.2 , following Laplace transformation:

$$
\begin{aligned}
& v_{1}(s)=0.5\left(w_{11}(s)+w_{22}(s)\right) \text { and } v_{2}(s)=0.5\left(w_{11}(s)-w_{22}(s)\right) \text {, then: } \\
& v_{1}(s)=0.5\left(\left(a_{h}+a_{l}\right)+(1+r) s\right) \text { and } v_{2}(s)=0.5\left(\left(a_{h}-a_{l}\right)+(1-r) s\right)
\end{aligned}
$$

If: $\left.\mu(s)=\left[0.25\left(w_{11}(s)-w_{22}(s)\right)^{2}+w_{12}(s) w_{21}(s)\right)\right]^{0.5}$

then with substitutions from equations 4.5 and 4.6 :

$$
\mu(s) \rightarrow \mu_{p}(s)=0.5\left[\left(a_{h}+a_{l}\right)^{2}+2\left(a_{h}-a_{l}\right)(1-r) s+(1-r)^{2} s^{2}\right]^{0.5}
$$

for a parallel flow heat exchanger and:

$$
\mu(s) \rightarrow \mu_{c}(s)=0.5\left[\left(a_{h}-a_{l}\right)^{2}+2\left(a_{h}+a_{l}\right)(1+r) s+(1+r)^{2} s^{2}\right]^{0.5}
$$

for a counter flow heat exchanger so that:

$$
\lambda_{1}(s)=-\mu(s)+v_{1}(s) \text { and } \lambda_{2}(s)=-\mu(s)-v_{1}(s)
$$

satisfying the condition:

$$
W(s) U(s)=U(s) \Lambda(s)
$$

where the elements of $W(s)$ are: $\boldsymbol{w}_{i j}(s), \mathbf{1} \leq i, j \leq \mathbf{2}$, given by equations 4.2 and the elements of: $U(s)$ and $\Lambda(s)$ are given by equations 4.4 and 4.5, respectively.

The decoupled solution is now available yielding:

$$
\theta(s)=U(s)\left[\begin{array}{lc}
e^{\lambda_{1}(s) z} & 0 \\
0 & e^{\lambda_{2}(s) z}
\end{array}\right] U^{-1}(s) \theta(0)
$$

Hence, the terminal, input-output response is given by:

$$
\left[\begin{array}{l}
\theta_{h 2}(s) \\
\theta_{l 2}(s)
\end{array}\right]=\left[\begin{array}{ll}
\gamma_{2}(s) e^{\lambda_{1}(s) z}-\gamma_{1}(s) e^{\lambda_{2}(s) z} & -e^{\lambda_{1}(s) z}+e^{\lambda_{2}(s) z} \\
\gamma_{1}(s) \gamma_{2}(s)\left(e^{\lambda_{1}(s) z}-e^{\lambda_{2}(s) z}\right) & -\gamma_{1}(s) e^{\lambda_{1}(s) z}+\gamma_{2}(s) e^{\lambda_{2}(s) z}
\end{array}\right]\left[\begin{array}{l}
\theta_{h 1}(s) \\
\theta_{l 1}(s)
\end{array}\right] \frac{1}{\left(\gamma_{2}(s)-\gamma_{1}(s)\right)}
$$


where in equation $4.11\left(\gamma_{2}(s)-\gamma_{1}(s)\right)=-2 v_{1}(s) / a_{h}$ and $z$ is given by equation 3.5.

\section{Transfer Function Form.}

The input-output- disturbance, admittance or transfer function form, for a shell- tube heat exchanger, is:

$y(s)=\bar{G}(s) u(s)+\delta(s)$

where in equation $5.1 \bar{G}(s)$ is the matrix from equation 4.11 with:

$z=Z / L=1, y(s)=\left(\boldsymbol{\theta}_{h_{2}}, \boldsymbol{\theta}_{l_{2}}\right), u(s)=\left(\boldsymbol{\theta}_{h_{1}}, \boldsymbol{\theta}_{l_{1}}\right)$ and $\boldsymbol{\delta}(s)$ represents the ambient temperature disturbances.

Hence, in equation 5.1:

$\bar{G}(s)=\left[\begin{array}{ll}\gamma_{2}(s) e^{\lambda_{1}(s)}-\gamma_{1}(s) e^{\lambda_{2}(s)} & -e^{\lambda_{1}(s)}+e^{\lambda_{2}(s)} \\ \gamma_{1}(s) \gamma_{2}(s)\left(e^{\lambda_{1}(s)}-e^{\lambda_{2}(s)}\right) & -\gamma_{1} e^{\lambda_{1}(s)}+\gamma_{2} e^{\lambda_{2}(s)}\end{array}\right] \frac{1}{\left(\gamma_{2}(s)-\gamma_{1}(s)\right)}$

\section{Pre- Heater and Post Heater Time Delays.}

To compensate for small variations in the fluid temperatures, at the shell and tube input and output ports, electrical heating elements may be used to facilitate this adjustment. This process imposes further delays so that:

$$
\theta_{h_{1}}(s) \rightarrow \theta_{h_{1}}(s) /\left(T_{1} s+1\right) \text { and } \theta_{l_{1}}(s) \rightarrow \theta_{l_{1}}(s) /\left(T_{2} s+1\right)
$$

If in equation 6.1:

$$
T_{1}(s)=T_{2}(s)=T(s),
$$

then:

$$
y(s)=G(s) u(s)+\delta(s)
$$

where in equation 6.2 the input vector: 


$$
u(s)=\left(\theta_{h_{1}}(s), \theta_{h_{2}}(s)\right)^{T} \text { and } G(s)=\bar{G}(\mathrm{~s}) /(T s+1) .
$$

\section{Rationalization of $\mu_{p}(s)$ for a Parallel Flow Heat Exchanger.}

In section 4, a problem arises in the form of the irrational Laplace function, see for example Spiegel M.R. (37), given by equation 4.7 and 4.8 , leading to the \pm separation of the frequency response loci at $s=0$.

A Bode plot, for a parallel flow heat exchanger, for the modulus of the function:

$$
\mu_{p}^{2}(s) / 0.25=\left(a_{h}+a_{l}\right)^{2}+2\left(a_{h}-a_{l}\right)(1-r) s+(1-r)^{2} s^{2},(s=i \omega)
$$

given by equation 7.1, would result in a low frequency gain of $20 \log _{10}\left(a_{h}+a_{l}\right)^{2}$ and a high frequency gain slope of $40 \mathrm{~dB}^{\prime} \mathrm{s} /$ decade with an anti - resonance frequency of $\omega_{r}=2\left(a_{h} a_{l}\right)^{0.5} /|(1-r)|$ rads / sec., where the damping ratio $\zeta=\left(a_{h}-a_{l}\right) \mid /\left(a_{h}+a_{l}\right) \leq 1$ for this low frequency application. The modulus curve for $\mu^{2}(s) / \mathbf{0 . 2 5}$ would result in a phase lead characteristic. A close approximation for this graph, could be obtained by the use of the function:

$$
\mu_{p}(s) / 0.25 \approx\left[\left(a_{h}+a_{l}\right)\left(1+\tau_{p} s\right)\right]^{2}
$$

Restoring thereby rationality with equation 7.1 becoming:

$$
\mu_{p}(s)=\left[\left(a_{h}+a_{l}\right)\left(1+\tau_{p}\right)\right] / 2
$$

as a first approximation, with a suitable choice for $\tau_{p}$. The application study of section 13 , will demonstrate the effectiveness of this simplification.

\section{Rationalization of $\mu_{c}(s)$ for a Counter Flow Heat Exchanger.}

Similarly, a Bode frequency response plot for a counter flow heat exchanger model with: 


$$
\mu_{c}^{2}(s) / 0.25=\left(a_{h}-a_{l}\right)^{2}+2\left(a_{h}+a_{l}\right)(1+r) s+(1+r)^{2} s^{2},(s=i \omega)
$$

would result in a low frequency gain of $20 \log _{10}\left(a_{h}-a_{l}\right)^{2}$ and a high frequency gain slope of $40 \mathrm{~dB}$ 's/decade with a:

damping ratio $\zeta=\left(a_{h}+a_{l}\right) /\left(a_{h}-a_{l}\right)>1$

for this low frequency, counter flow, system model.

The frequency response curve results in a phase lead characteristic corresponding to the function:

$$
\mu_{c}(s) / 0.25 \approx\left[\left|\left(a_{h}-a_{l}\right)\right|\left(1+\tau_{c} s\right)\right]^{2}
$$

and this could be employed. There is no resonance condition for this application since: $v>1$. With the function of equation 8.2, rationality would be restored with equation 8.1 becoming:

$$
\mu_{c}(s)=\left[\left|\left(a_{h}-a_{l}\right)\right|\left(1+\tau_{c} s\right)\right] / 2
$$

again with a suitable choice, in equation 8.3 , for $\tau_{c}$. The application study of section 14 , illustrates the effectiveness of this simplification.

\section{Block diagram for the Parallel Flow Heat Exchanger.}

The block representation for a parallel flow heat exchanger model including the heater time delays of $1 /(T s+1)$, is given in figure 4 . This configuration reflects equation 6.2 , including the disturbances, where the eigenvalues and eigenvectors are used to formulate the input, output model and the connecting distance- velocity, time delay blocks.

Essentially, $\mathrm{G}(\mathrm{s})$ in equation 6.2 , in spectral form becomes: 


$$
\left[\begin{array}{l}
\theta_{h_{2}}(s) \\
\theta_{l_{2}}(s)
\end{array}\right]=U(s)\left[\begin{array}{ll}
e^{\lambda_{1}(s)} & 0 \\
0 & e^{\lambda_{1}(s)}
\end{array}\right] U^{-1}(s)\left[\begin{array}{l}
\theta_{h_{1}}(s) \\
\theta_{l_{1}}(s)
\end{array}\right] /(T s+1),
$$

where in equation 9.1

$\lambda_{1}(s), \lambda_{2}(s), \gamma_{1}(s), \gamma_{2}(s)$ and $U(s)$ are given by equations 4.9 and 4.4 , respectively and:

$$
U(s)^{-1}=\left[\begin{array}{cc}
\gamma_{2}(s) & -1 \\
-\gamma_{1}(s) & 1
\end{array}\right] /\left(\gamma_{2}(s)-\gamma_{1}(s)\right)
$$

The $\alpha(s)$ and $\beta(s)$ signals, in figure 4 are obtained from the eigenvectors where:

$$
\left(U^{-1}(s)\left(\theta_{h_{1}}(s), \theta_{l_{1}}(s)\right)^{T} /(T s+1)=(\alpha(s), \beta(s))^{T}\right.
$$

and

$$
\left(\left(\theta_{h_{2}}(s), \theta_{l_{2}}(s)\right)^{T}=U(s)\left[(\alpha(s), \beta(s))^{T}\right] /(T s+1)\right.
$$

\section{Block diagram for the Counter Flow Heat Exchanger.}

In this case the boundary values from equation 4.11 can be used to determine the alpha and beta signals. Here at $z=0$ and $z=1$, where $z=Z / L$, excluding the pre and post heater functions:

$$
\theta_{h}(s)=\left[\left(\gamma_{2}(s) \theta_{h_{1}}(s)-\theta_{l_{1}}(s)\right) e^{\lambda_{1}(s) z}+\left(-\gamma_{1}(s) \theta_{h_{1}}(s)+\theta_{l_{1}}(s)\right) e^{\lambda_{2}(s) z}\right] /\left(\gamma_{2}(s)-\gamma_{1}(s)\right)
$$

$$
\theta_{l}(s)=\left[\gamma_{1}(s)\left(\gamma_{2}(s) \theta_{h_{1}}(s)-\theta_{l_{1}}(s)\right) e^{\lambda_{1} z}+\gamma_{2}(s)\left(-\gamma_{1}(s) \theta_{h_{1}}(s)+\theta_{l_{1}}(s)\right) e^{\lambda_{2} z}\right] /\left(\gamma_{2}(s)-\gamma_{1}(s)\right)
$$

With: $\alpha(s)=\left(\gamma_{2}(s) \theta_{h_{1}}(s)-\theta_{l_{1}}(s)\right) /\left(\left(\gamma_{2}(s)-\gamma_{1}(s)\right)\right.$ and $\beta(s)=\left(-\gamma_{1}(s) \theta_{h_{1}}(s)+\theta_{l_{1}}(s)\right) /\left(\gamma_{2}(s)-\gamma_{1}(s)\right)$ 
Consequently, at $z=\mathbf{0}$ :

$\theta_{h 1}=\alpha(s)+\beta(s) \quad 10.3$

and at $z=\mathbf{1}$ equation 10.2 becomes :

$\left(\alpha(s) \gamma_{1}(s) e^{\lambda_{1}(S)}+\beta(s) \gamma_{2}(s) e^{\lambda_{2}(s)}\right)=\theta_{l 1}$ so that: $\quad \mathbf{1 0 . 4}$

$$
\left(\theta_{h 1}, \theta_{l 1}\right)^{T}=\left[\begin{array}{ll}
1 & 1 \\
\gamma_{1} e^{\lambda_{1}(s)} & \gamma_{2} e^{\lambda_{2}(s)}
\end{array}\right]\left[\begin{array}{l}
\alpha(s) \\
\beta(s)
\end{array}\right],
$$

Also :

$$
\left[\begin{array}{l}
\theta_{h_{2}}(s) \\
\theta_{l_{2}}(s)
\end{array}\right]=\left[\begin{array}{lc}
e^{\lambda_{1}(s)} & e^{\lambda_{2}(s)} \\
\gamma_{1}(s) e^{\lambda_{1}(s)} & \gamma_{2}(s) e^{\lambda_{2}(s)}
\end{array}\right]\left[\begin{array}{l}
\alpha(s) \\
\beta(s)
\end{array}\right] \quad 10.5 .
$$

From the terminal relationships, given by equations 10.4 and 10.5 , the block diagram representation for the counter flow heat exchanger can be constructed, as shown in figure 5 . This is used in the application study of section 14, where the pre and post heater and delays, at the inputs and outputs have been included, for completeness.

\section{Parallel Flow Heat Exchanger, Application Study.}

In this study, a shell and tube, parallel flow, heat exchanger which is equivalent to the arrangement shown in figures 1 a and 2 , with a fluid path length of $L=10.4 \mathrm{~m}$ will be investigated.

If the fluid and heat transfer parameters are:

$v_{h}=2 \mathrm{~m} / \mathrm{sec}$ and $v_{l}=\mathbf{1} \mathrm{m} / \mathrm{sec}$ and in equations 3.5 and 3.6 the heat capacitance and conductance parameters are: 
$L_{h}=5.2 \mathrm{sec}, L_{l}=10.4 \mathrm{sec}, r=2, C_{h}=1, C_{l}=1$ and $R=5$ then:

$a_{h}=\mathbf{1 . 0 4}$ and $a_{l}=\mathbf{2 . 0 8}$.

These procedures relate the input and output tube and shell, fluid flow temperatures and distance-velocity delays. From the frequency response, Bode amplitude diagram of figure 6 , for

$\mu_{p} / 0.25=9.7344+2.08 s+s^{2}$ and $\mu_{p} / 0.25 \approx 9.7344\left(1+\tau_{p} s\right)$ with: $\tau_{p}=4$ sec

This provides a suitable approximation for $\mu_{p}(s)$ enabling the restoration of rationality. With the inclusion of the exponential heater delays of $T=10$ secs., the system specification, for the parallel flow heat exchanger model, may be formulated.

Inserting these values in equations $4.4,4.9$ and 7.3 with $\tau_{p}=\mathbf{4 . 0} \mathbf{s e c} s$. results in:

$\gamma_{1}(s)=1-3.5961 s, \gamma_{2}(s)=-2(1+3.2403 s), \lambda_{1}(s)=-4.740 s, \lambda_{2}(s)=-3.12(1+2.481 s)$, and $\gamma_{1}(s)-\gamma_{2}(s)=-3(1+0.9615 s)$

enabling the construction of the block representation and dynamic analysis.

\section{Counter Flow Heat Exchanger, Application Study.}

All of the functions given in section 4, for the parallel flow heat exchanger remain valid for the counter flow model, again with $\mathrm{T}=10 \mathrm{sec}$, with the frequency response time constant, now specified as $\tau_{c}$. From the Bode amplitude diagrams for:

$\mu_{c} / 0.25=1.0816+18.72 s+9.0 s^{2}$, and $\mu_{c} / 0.25 \approx 1.0816\left(1+\tau_{c} s\right)^{2}$ with $\tau_{c}=1.01$. are as shown in figure 7 , where a suitable fit is evident enabling the rationalization of $\mu_{c}(s)$ by using this approximation. Inserting the values given in section 9, for the counter flow relationships, given in section 8, results in: 


$$
\begin{aligned}
& \gamma_{1}(s)=1-0.9038 s, \gamma_{2}(s)=-2(1+0.9903 s), \lambda_{1}(s)=-0.06 s, \lambda_{2}(s)=-3.12(1+0.9810 s) \\
& \text { and } \gamma_{1}(s)-\gamma_{2}(s)=-3(1+0.9615 s)
\end{aligned}
$$

from equations 4.3, 4.9 and 8.3. These functions are required, for dynamic analysis purposes.

\section{Simulation for the Parallel Flow, Heat Exchanger.}

The only functions and coefficients required for the simulation of the parallel flow, tubular heat exchanger model, given in block diagram form in figure 4, which is constructed from equation 6.2, are: $\gamma_{1}(s), \gamma_{2}(s), \lambda_{1}(s), \lambda_{2}(s), T$ and $\tau_{p}$, given in section 11 .

Step input changes on the low and high temperature flow streams give the output temperature transients shown in figure 8a, for input changes of $\boldsymbol{\theta}_{h_{1}}=\mathbf{1 0 0}$ degrees, $\boldsymbol{\theta}_{l_{1}}=\mathbf{1 0}$ degrees, respectively. over an interval of $100 \mathrm{sec}$. These graphs indicate that $\theta_{h_{2}}(t)$ falls from 100 to 73.1673 at $\theta_{h_{2}}(t)$ and $\theta_{l_{2}}(t)$ rises from 10 to 73.1673 degrees at $\theta_{l_{2}}(t)$ in approximately 80 seconds. A small non-minimum phase effect is also evident on $\boldsymbol{\theta}_{l_{2}}(\boldsymbol{t})$ resulting in an initial fall in this temperature owing to cross -flow, temperature interaction.

Figure $8 \mathrm{~b}$ shows the steady state, distance- temperature distribution, for the same input changes with the high temperature stream falling to 73.1673 and the low temperature stream rising to 67.3293 degrees. These temperature, distribution characteristics are typical, for parallel flow heat exchanger.

\section{Simulation for a Counter Flow, Heat Exchanger.}

The simulation block representation, for the counter flow heat exchanger, can be constructed from the series, system block diagram realization, given by equations 10.4 and 10.5 . However, 
the fluid flows at temperature $\theta_{l_{1}}$ and $\theta_{l_{2}}$ require interchanging in order to reflect the counter flow heat exchanger topology. The only elements required for the simulation are given in section 12 for:

$$
\gamma_{1}(s), \gamma_{2}(s), \lambda_{1}(s), \lambda_{2}(s), T \text { and } \tau_{c}
$$

The block representation structure is as shown, in the admittance diagram of figure 5.

Again, for step input changes on the low and high temperature flow streams of $\theta_{h \mathbf{1}}=\mathbf{1 0 0}$ degrees $\theta_{l 1}=\mathbf{1 0}$ degrees, respectively. the output temperature transient changes are as shown in figure 9a, for an interval of 100 sec., with $\theta_{h 1}(t)$ falling from 100 to $42.6184^{\circ}$ at $\theta_{h 2}(t)$ and $\theta_{l 1}(t)$ rising from 10 to $38.6993^{\circ}$ at $\theta_{l 2}(t)$, in approximately 80 seconds. Figure $9 \mathrm{~b}$ shows the steady state, distance- temperature distribution, for the same input, temperature changes, with the high temperature stream falling to $42.6184^{\circ}$ and the low temperature stream rising to $38.6993^{\circ}$ at their respective outputs. These steady state, distance-temperature, distribution characteristics are typical, for counter flow heat exchangers.

\section{Conclusion.}

In this contribution the dynamic modelling process for tube and shell, heat exchangers, was outlined. The complexity of the representations for these devices, arises from the fact that under independent, fluid flow and input-output temperature conditions, the analytical procedures result in multivariable, irrational, two dimensional models. This inhibits direct Laplace inversion to the time domain whilst restricting simulation and analytical evaluation. It is true, that in principle the Laplace error function and contour integration could be employed to achieve the time domain functions required. However, this process becomes 
increasingly challenging when considering the mixed, lumped and distributed parameter models, employed herein.

These models exhibit Laplace function singularities, further limiting investigation, under general tube and shell, fluid/ gas flow and temperature variation conditions. This impedes simulation, design and the application of feedback regulation with the result that the prediction of optimum, continuous operational, dynamic performance, is difficult.

With the use of frequency response, Bode analysis procedures, it was demonstrated that Laplace rationality can be restored with the result that design and simulation becomes easier opening the route to feedback regulation and optimization studies. The key to this depends on achieving a suitable low frequency fit, for the parallel and counter flow model, $\mu_{p}(s)$ and $\mu_{c}(s)$ functions, respectively. In doing so, the complex frequency domain, branch point problem is avoided with the restoration of Laplace function completeness.

As shown in sections 7 and 8 and in sections 13 and 14, of this contribution, the dynamic simulation of both parallel and counter flow, tubular heat exchanger models following this enhancement becomes routine enabling the application of conventional analysis and simulation methods and the advancement of the design and feedback control problems.

Since large tubular heat exchangers are often exposed to direct sunlight, radiant heating and substantial atmospheric temperature fluctuations often occur. This exacerbates the heat transfer intensity and hence the achievement of specific temperature input- output changes, as a result of these disturbances which may be considerable, in many geographical locations. The approach adopted herein should enable rapid progress to be made in the quest for a feedback solution to the disturbance suppression and rapid recovery problem, whilst improving the response characteristics, for shell and tube heat exchangers. Hopefully, this viability study should assist in the attainment of this objective. 


\section{References}

1. Saunders E. A., 'Heat Exchangers: Selection, Design and Construction', Longmans, New York, 1988.

2. Hewitt G., Shires G. and Bott T., 'Process Heat Transfer', CRC Press, Boca Raton, Florida, 1994.

3. Coulson J and Richardson J, 'Chemical Engineering- Fluid Flow, Heat Transfer and Mass Transfer', Reed Pub., London, 1999.

4. Smith B. W., 'Designing and Control of Papermaking Systems', Trans. British Paper and Board Makers Assoc., Oxford, 1970.

5. Sadik K. and Liu H.,' Heat Exchangers: Selection, Rating and Thermal Design ', CRC Press, Boca Raton, Florida, 2002.

6. Advances in Thermal Design of Heat Exchangers: A Numerical Approach: Direct-Sizing, Step-Wise Rating, and Transients, Copyright (C) 2005 John Wiley \& Sons, Ltd, Dr. Eric M Smith, Published Online: 6 FEB 2006, ISBN: 9780470016169 ; DOI: 10.1002/0470017090

7. Whalley R. and Ameer A., 'Heating, Ventilation and Air Conditioning System Modelling', Proc. IMech, pt. I, Vol. 42, 2002, pp 643- 656.

8. Roetzel, W. and Xuan, Y. Dynamic Behaviour of Heat Exchangers, WIT Press, Boston (1999)

9. Whalley R., 'The Mathematical Model for a Naval Boiler', Trans Inst. MC, Vol. 11, No. 9, 1978.

10. Schultz M. A.,' Control of Nuclear Reactors', McGraw-Hill, New York, 1961.

11. Lienhard H. and Lienhard H.," A Heat Transfer Textbook", Philogiston Press, Cambridge, Mass., 2012.

12. Kraus A. D., Welty J.R and Aziz A.,' Introduction to Thermal and Fluid Engineering', CRC Press, Boca Raton, Florida, 2011.

13. Bennett C. O. and Myers J. E., 'Momentum, Heat and Mass Transfer ', McGraw-Hill, 1983.

14. Taler, D. ,Dynamic response of a cross-flow tube heat exchanger, Chemical and Process Engineering, Vol. 27, No. 3/2 , 1053-1071, 2006, PL ISSN 0208-64-25.

15. Taler, D. , Analytical and numerical model of transient heat transfer in a single tube row heat exchanger, 2007, Archives of Thermodynamics 28(1):51-64.

16. Cengel Y A, 'Heat Transfer', McGraw-Hill, New York, 2003. 
17. Taler, D., Direct and inverse heat transfer problems in dynamics of plate fin and tube heat exchangers, A. Belmiloudi (Ed.), Heat Transfer, Mathematical Modelling, Numerical Methods and Information Technology, InTech, Rijeka (2011), pp. 77-100 mathematicalmodelling-numerical-methods-and-information-technology.

18. DuChateau P. and Zachmann D., 'Partial Differential Equations', Schaum, New York, 1986.

19. Jost J., 'Partial Differential Equations', Springer, New York, 2002.

20. Korzeń A., Taler D., Modeling of transient response of a plate fin and tube heat exchanger, International Journal of Thermal Sciences, Volume 92, June 2015, Pages 188-198.

21. Whalley R., 'Agile Computer Control and Surveillance Systems', IEE Proc. Vol. 138, No 3, 1991, pp185-192.

22. Whalley R. and Zeng Z., 'Two Dimensional Computer Control System Analysis', Proc. IMechE pt I, Vol. 206, No 11, pp , 1992.

23. Schwartz R S and Friedland B, 'Linear Systems', McGraw- Hill, New York, 1963.

24. Dutton K, Thompson S and Baraclough R, 'The Art of Control Engineering', Addison Wesley, Harlow, 1997.

25. Rosenbrock H. H, 'Computer Aided Control System Design', Academic Press, 1974.

26. Reddy J N, 'An Introduction to Finite Element Method ', McGraw- Hill, New York, 2005.

27. Profos P, 'Dynamics of Superheater Control ', Combustion, No 31, 1959.

28. Maciejowsi J.M,"Multivariable Feedback Design”, Addison-Wesley, Wokingham, 1989.

29. Sala P.A, "Multivariable Control Systems", Springer, London, 2004.

30. Whalley R. and Ebrahimi M., 'Automotive Gas Turbine Regulation', IEEE Trans Control System Tech, Vol 12 (4), pp 405-475, 2004.

31. Whalley R. and Ebrahimi M., 'Multivariable System Regulation', Proc. IMechE, pt C, Vol 220, pp 653-667, 2006.

32. Incoopera, F.P. Lavine. A.S. and DeWitt. D.P, "Fundamentals of Heat and Mass Transfer", J. Wiley, London, 2007.

33. Romie, F. E., Transient response of counterflow heat exchanger. Trans. ASME J. Heat Transfer 106 (1985) 620-626

34. Romie, F. E., Transient response of the parallel-flow heat exchanger. Trans. ASME J. Heat Transfer 107 (1986) 727-730 
35. Takahashi, Y, Rabins, M.I. and Auslander, D. M., "Control and Dynamics", AddisonWesley, Reading, Mass., 1972.

36. Barnett, S., "Matrices: Methods and Applications", Clarendon, Oxford, 1990.

37. Spiegel, M.R., " Laplace Transforms", Schaum, New York,1965. 


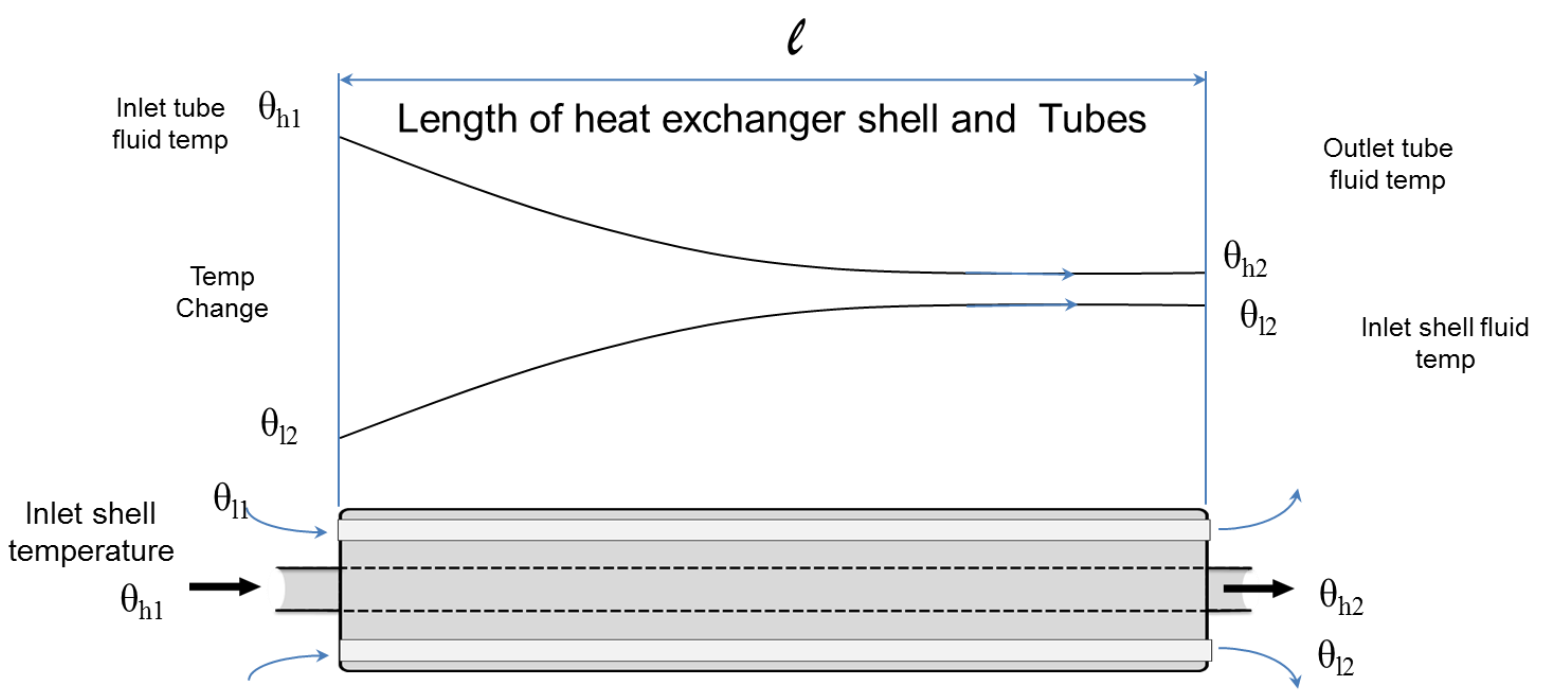

a) Parallel flow heat exchanger

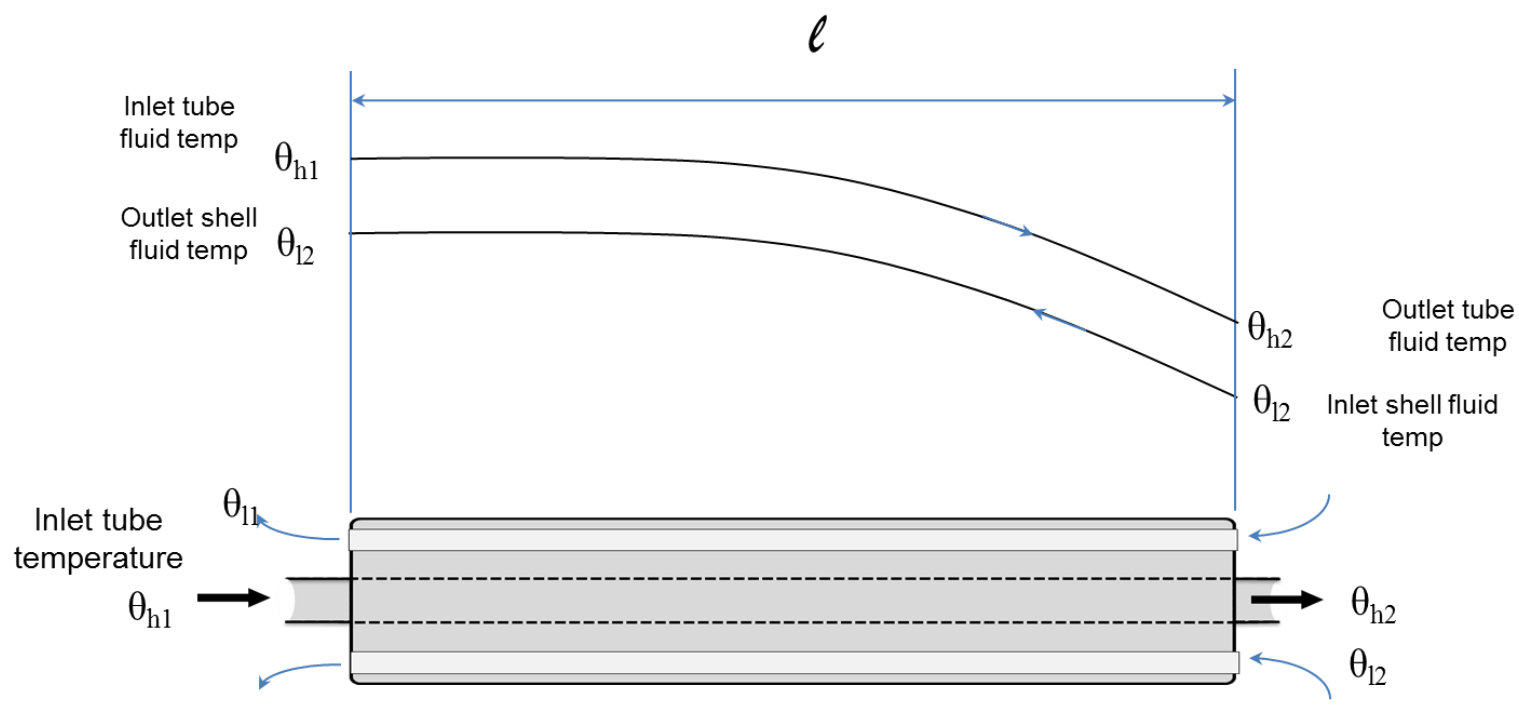

b) Counter flow heat exchanger

Figure 1 showing parallel and counter flow heat exchangers 


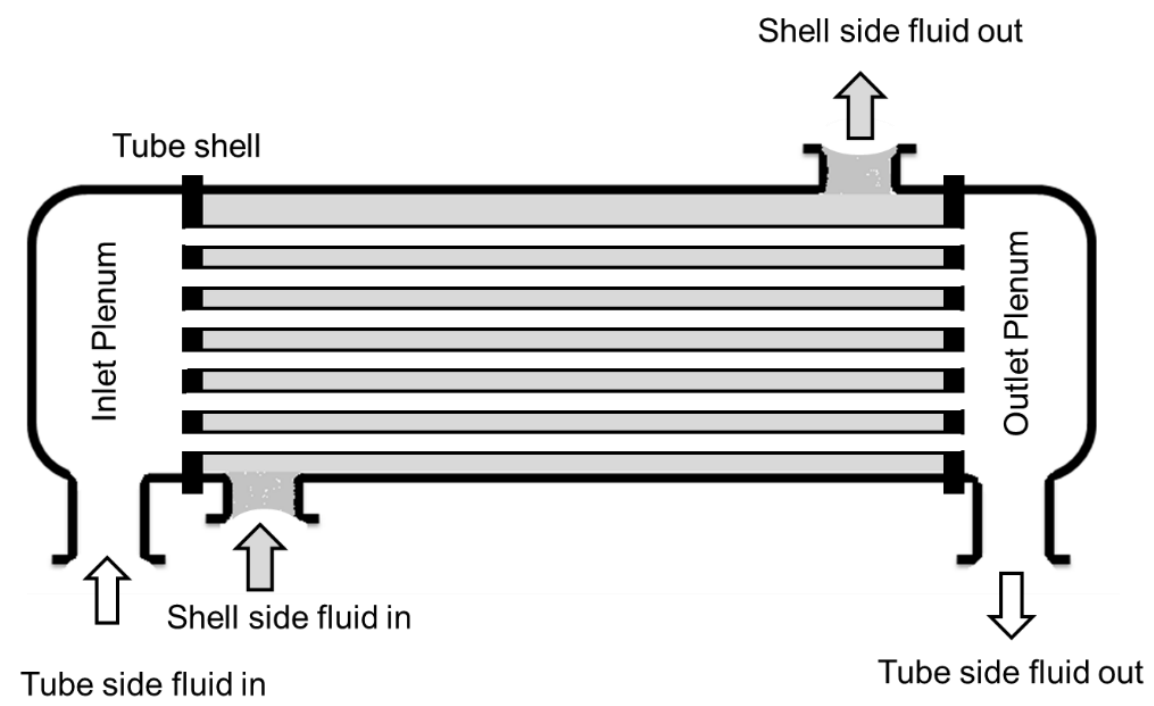

Figure 2 Shell and tube heat exchanger

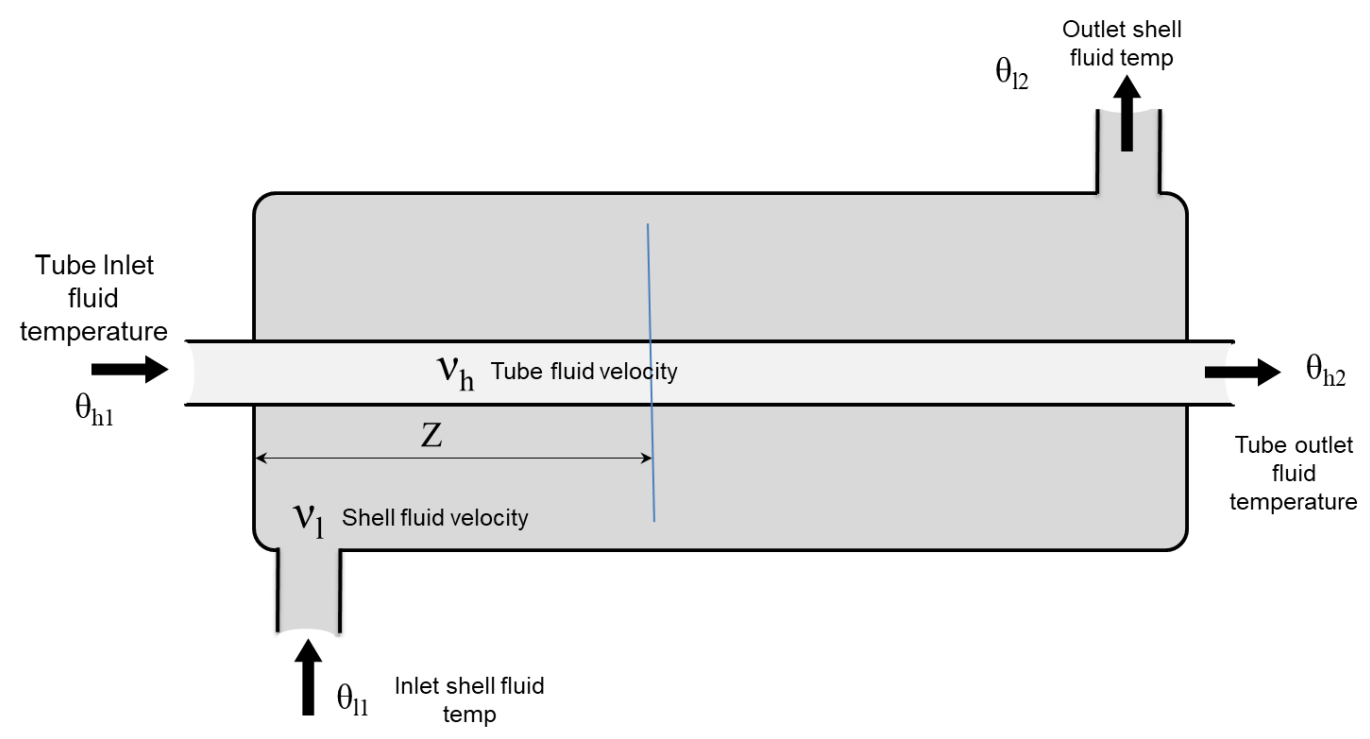

Figure 3 Parallel flow heat exchanger showing the parameters for analysis purposes 


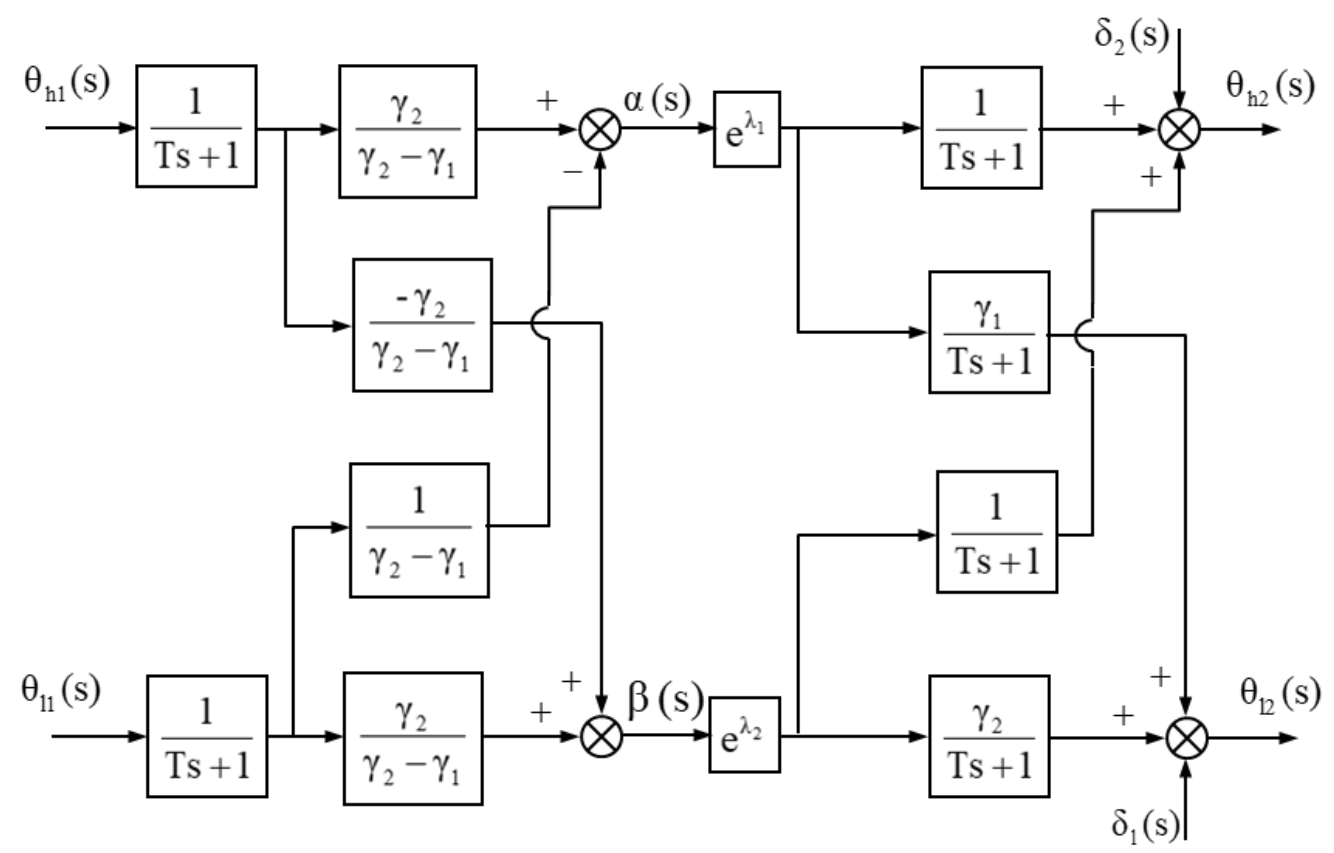

Figure 4 Parallel flow heat exchanges admittance diagram

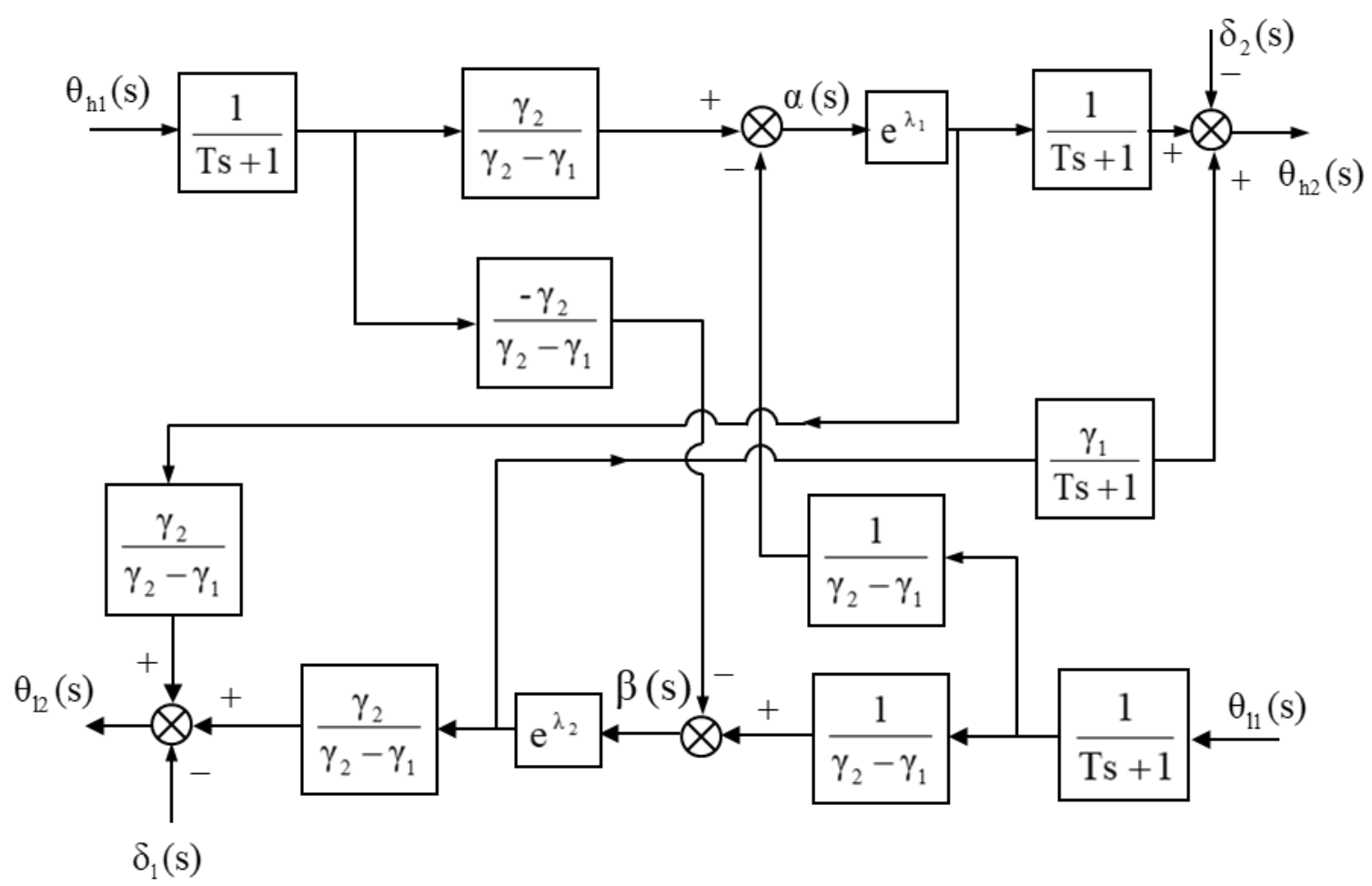

Figure 5 Counter flow heat exchanges admittance diagram 


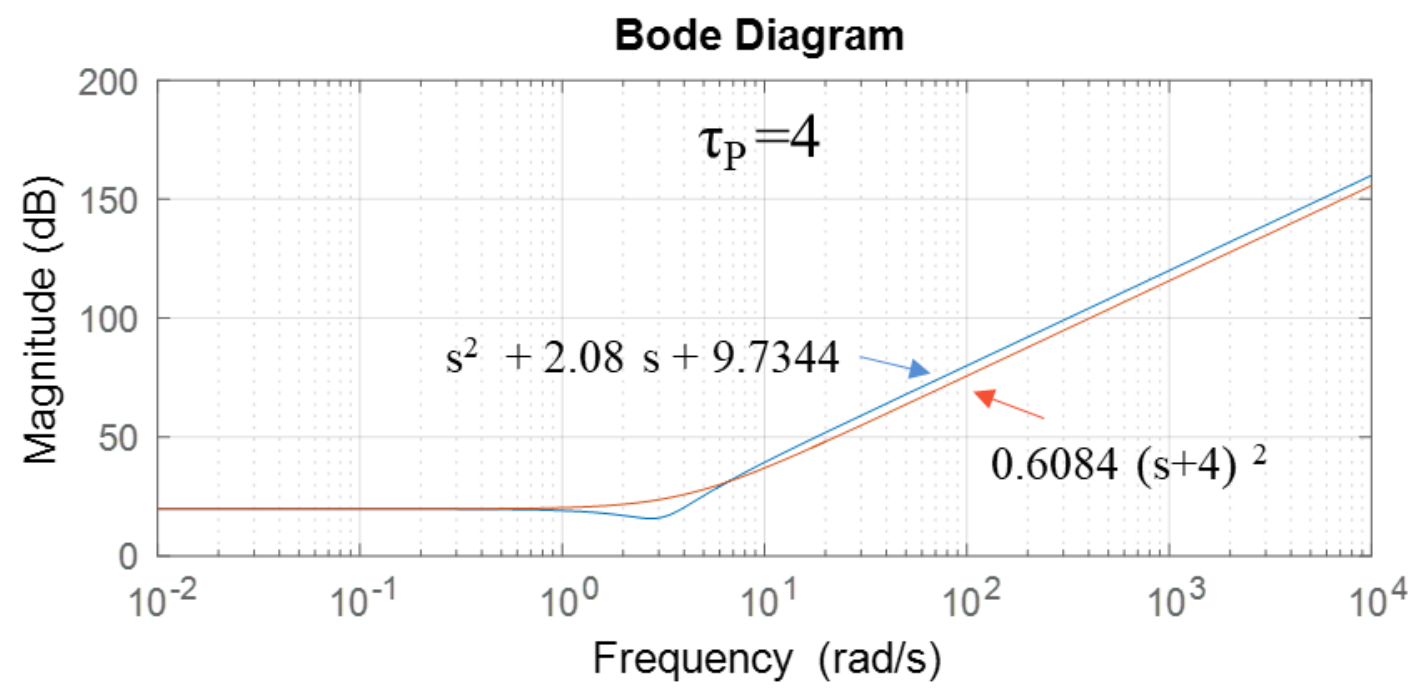

Figure 6, Bode amplitude diagram for parallel flow heat exchanger for $\mu_{P}(s) / 0.25=s^{2}+2.08 s+9.7344$ and $\mu_{P}(s) / 0.25=0.6084(s+4)^{2}$

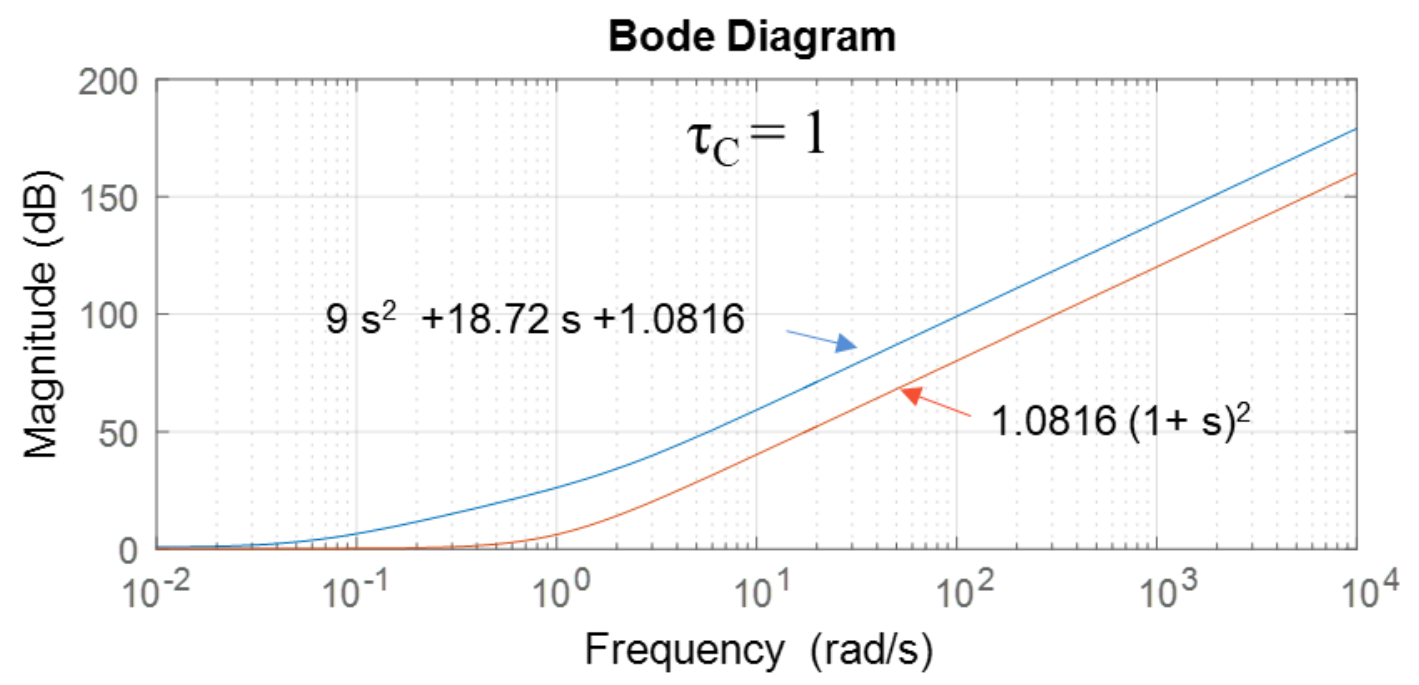

Figure 7, Bode amplitude diagram for counter flow heat exchanger for

$$
\begin{gathered}
\mu_{c}(s) / 0.25=9 s^{2}+18.72 s+1.0816 \text { and } \\
\mu_{c}(s) / 0.25=N=1.0816(1+s)^{2}
\end{gathered}
$$




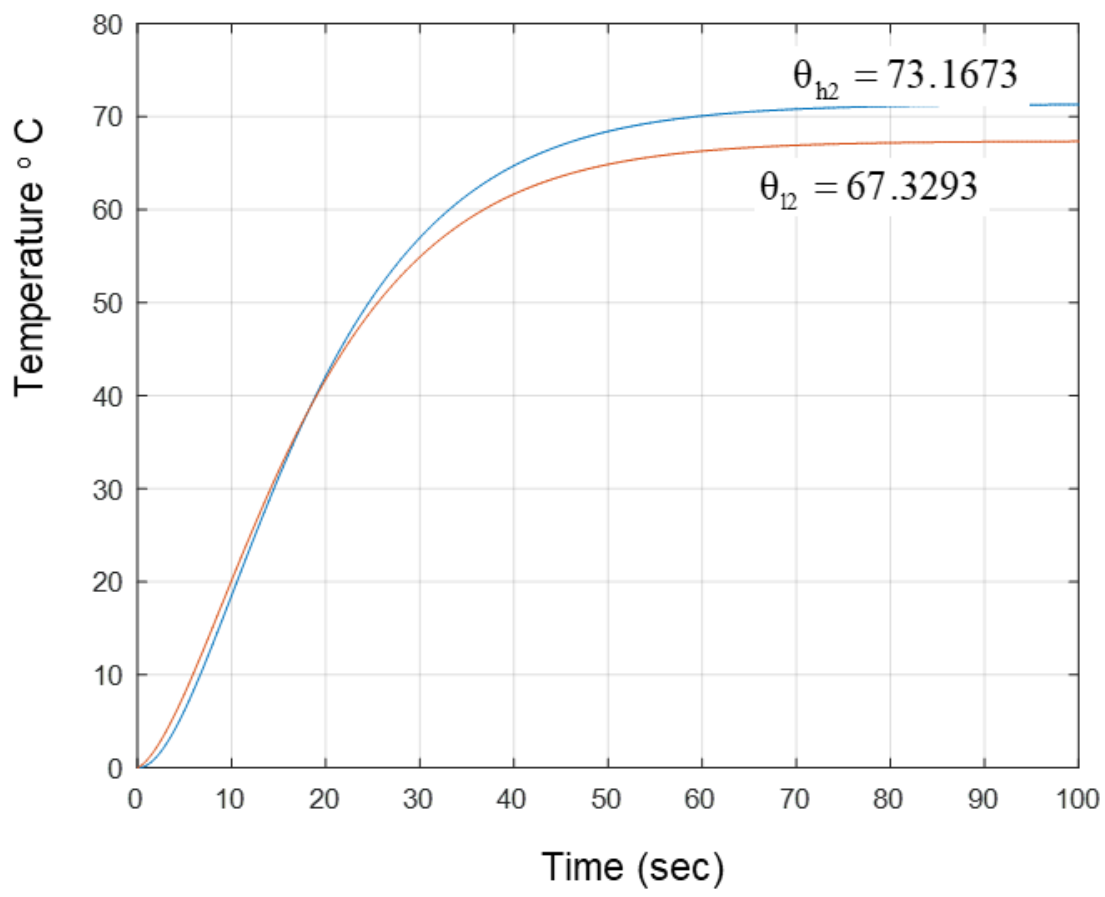

Figure 8.a Transient response for parallel flow heat exchanger following input step changes of $\theta_{\mathrm{h} 1}=100$ and $\theta_{\mathrm{l} 1}=10$ degrees

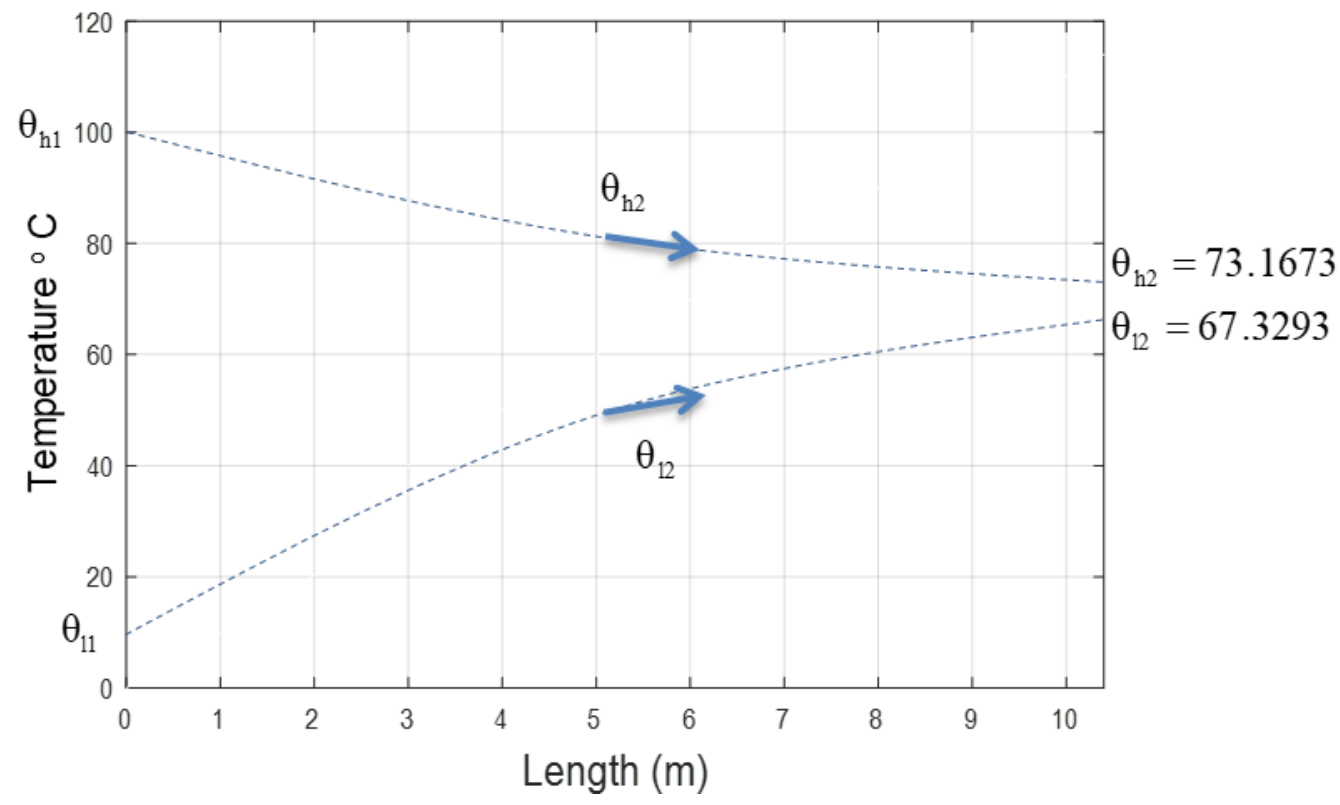

Figure 8.b Parallel flow heat exchanger, steady state temperature -distance distribution for $\theta_{\mathrm{h} 1}$ to $\theta_{\mathrm{h} 2}$ and $\theta_{11}$ to $\theta_{12}$. 


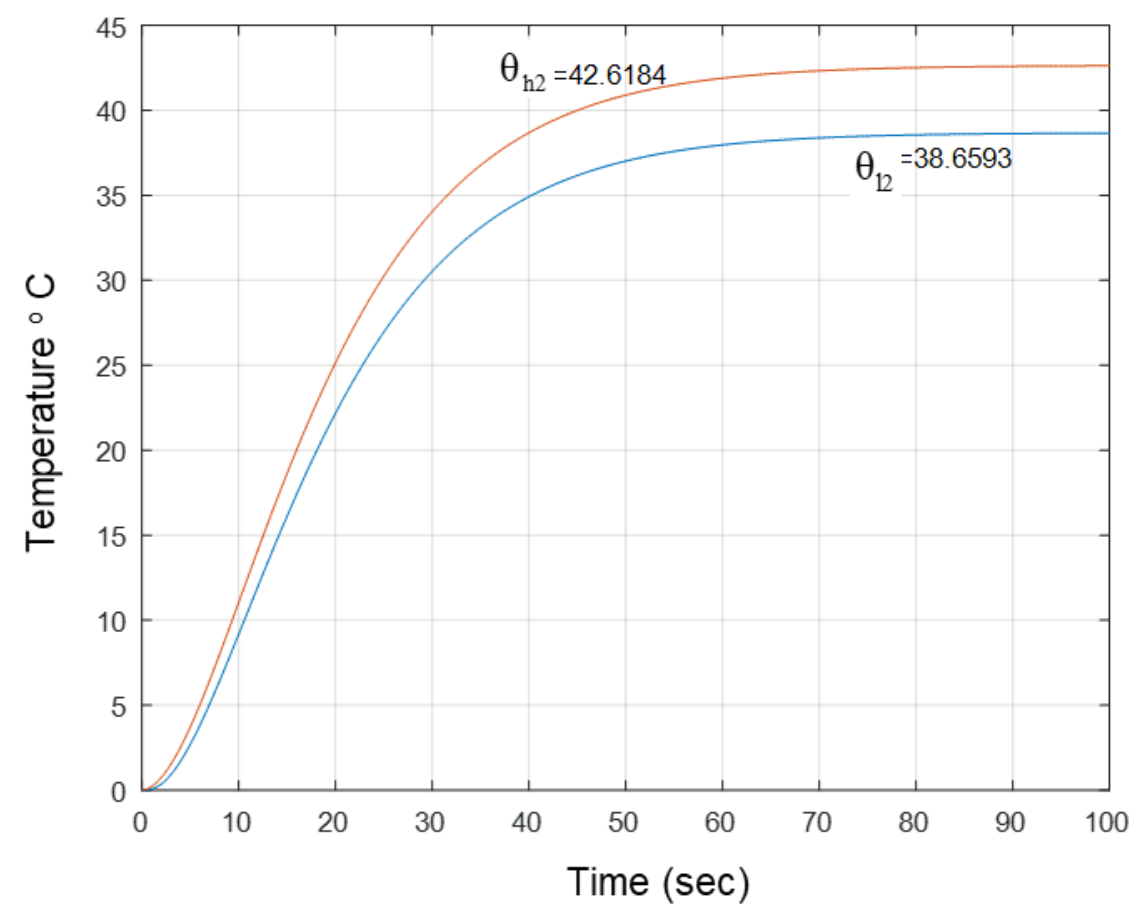

Figure 9.a Transient response for counter flow heat exchanger following input step changes of $\theta_{\mathrm{h} 1}=100$ and $\theta_{\mathrm{l} 1}=10$ degrees.

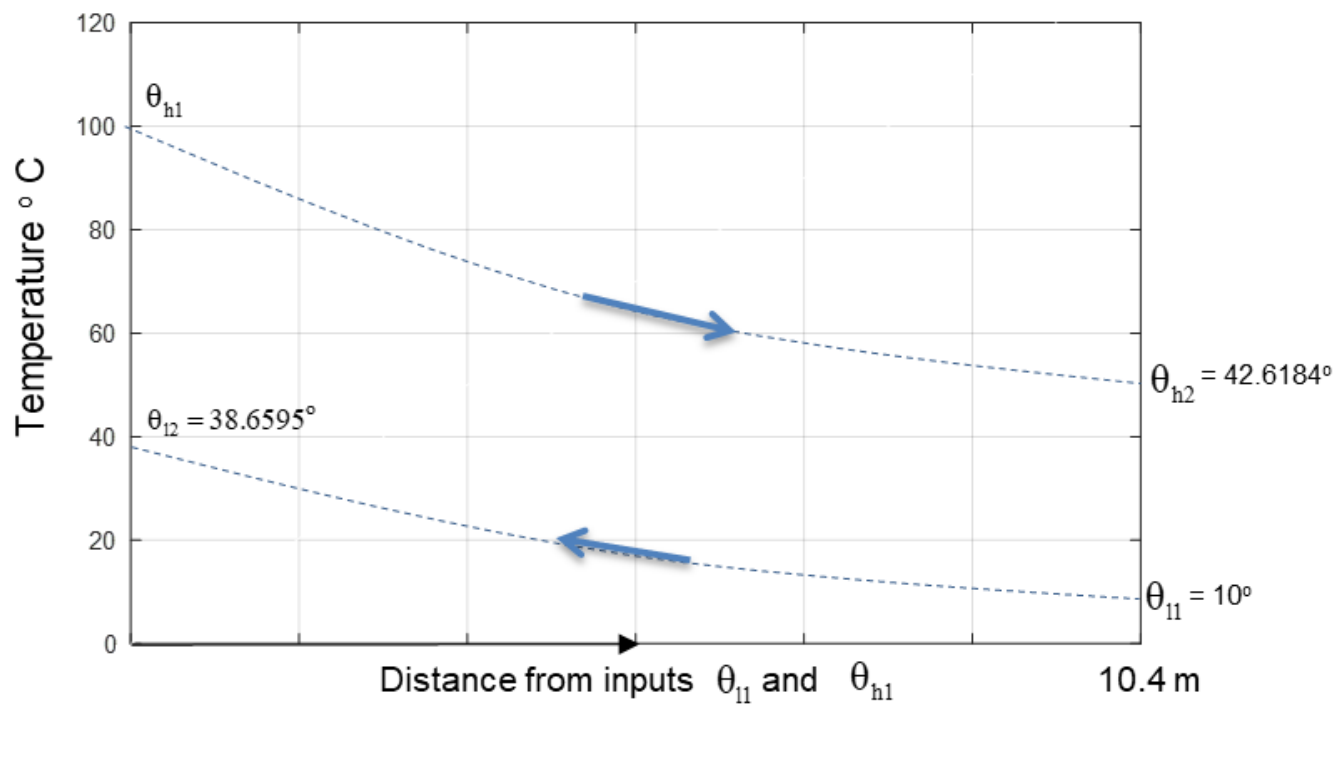

Figure 9.b Counter flow heat exchanger, steady state temperature -distance distribution for $\theta_{\mathrm{h} 1}$ to $\theta_{\mathrm{h} 2}$ and $\theta_{11}$ to $\theta_{12}$. 